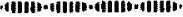
Transaction

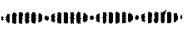

(Received July 1, 1986)

\title{
GRAFT COPOLYMERIZATION ONTO CHITOSAN BY PHOTO-INDUCED AND INITIATOR METHOD ${ }^{* 1}$
}

\author{
By Akira Takahashi, Yasusato Sugahara and Yoshiteru Horikawa \\ (Department of Industrial Chemistry, Faculty of Engineering, \\ Kogakuin University, Shinjuku-ku, Tokyo, 160, Japan)
}

\begin{abstract}
The graft copolymerization of methyl methacrylate onto chitosan was carried out, and the following results were obtained.

1) In the case of the non-catalytic photo-induced method, an induction period was observed and the polymerization proceeded mainly by the photolysis of amino groups.

2) In case of the photosensitized method, the grafting activity of azobisisobutylonitrile was higher than that of $\mathrm{ph}_{2} \mathrm{CO}$.

3) In the initiator method, the grafting activity of ammonium persulfate was higher than that of $\mathrm{H}_{2} \mathrm{O}_{2}$.

The degree of grafting and the apparent number of grafted chains generally decreased in the following order; the initiator method $>$ the photo-induced method without catalyst $>$ the photoinduced method with photosensitizer.

As for the photo-induced graft copolymerization of binary monomers (AN-MMA and AN-St) in the presence of chitosan, the monomer reactivity ratios of the graft and the ungrafted copolymer almost coincided with the values of the literature obtained in homogeneous system.
\end{abstract}

\section{INTRODUCTION}

For the purpose of utilization of chitin and chitosan, many studies on these chemical reactions have been carried out recently. However, a few papers on the graft copolymerization are reported, e.g., the graft copolymerization of methyl methacrylate onto chitin using tributylborane initiator ${ }^{1)}$ and of styrene onto chitin and chitosan by the radiation method ${ }^{2)}$. Especially, the characterization study of the copolymer obtained has not been reported.

Optical activity was found for the polymer obtained by radical polymerization of methyl methacrylate ${ }^{3)}$ initiated with chitosan $\mathrm{Cu}$ (II) complex, and the polymers of methacrylic acid ${ }^{4}$ ) and sorbic acid ${ }^{5)}$ obtained in the presence of chitosan.

In the present study, methyl methacrylate was grafted onto chitosan by a photo-induced method

*1 Studies on Graft Copolymerization onto Cellulose Derivatives (part 28). with and without photosensitizers, and by an initiator method. Then the effects of many factors on the yield of polymerization, the branched chain length and the apparent number of grafted chains of the copolymer are discussed. Furthermore, binary monomers were polymerized by the photo-induced method without a catalyst and the monomer reactivity ratios were also investigated.

\section{EXPERIMENTAL}

\subsection{Chitosan Sample and Monomer}

Chitosan sample offered from Kyowa-Yushi Co., Ltd. was purified by the following method before use. Chitosan $(10 \mathrm{~g})$ was dissolved in $5 \% \mathrm{CH}_{3} \mathrm{COOH}$ $(250 \mathrm{ml})$ and the insoluble part was removed. The solution was neutralized with $5 \%$ aqueous $\mathrm{NaOH}$. After an overnight stirring, the precipitant was washed with water, methanol and then ethyl ether.

Methyl methacrylate (MMA), styrene (St) and acrylonitrile (AN) were distilled in nitrogen at reduced or atmospheric pressure. 


\subsection{Graft Copolymerization}

Chitosan $(0.2 \mathrm{~g})$ was placed in a quartz $(\mathrm{Q})$ or pyrex (P) tube of $15 \mathrm{~mm}$ in diameter and $110 \mathrm{~mm}$ long. Water, solvent, monomer and initiator were then added to it and flushed with nitrogen gas (total volume, $12 \mathrm{ml}$ ). The reaction tube was fixed in a Riko rotary photo chemical reactor and the graft copolymerization was carried out by irradiating with a $160 \mathrm{~W}$ low pressure mercury lamp at an interval of $75 \mathrm{~mm}$.

The polymerization reaction was terminated by adding a saturated aqueous hydroquinone solution. The polymerized mixture was poured into a large amount of methanol $(250 \mathrm{ml})$ and precipitated. The homopolymer ( $\mathrm{p}$-MMA) was removed by extracting thoroughly with hot acetone, and the copolymers (AN-MMA and AN-St) were treated with hot acetone and then hot mixture of acetone/ dimethylformamide (DMF) (6/4 in volume). The remaining product was considered as grafted copolymer and the yield of polymerization was calculated as described in the previous paper ${ }^{6}$ )

2.3 Isolation of Grafted Chains and Measurement of Molecular Weight

Chitosan-G-p-MMA $(0.3 \mathrm{~g})$ was hydrolyzed in $100 \mathrm{ml}$ of $6 \mathrm{~N} \mathrm{HCl}$ at $100^{\circ} \mathrm{C}$ for $6 \mathrm{hr}$. The hydrolyzed solution was diluted to $1.5 l$ with water and filtered after overnight. The resultant crude p-MMA was dissolved in benzene and purified by reprecipitation. The intrinsic viscosity was measured in benzene. The molecular weight was calculated by the following equation ${ }^{\text {). }}$.

$$
\log \mathrm{Pn}_{n}=3.346+1.32 \log [\eta], 30^{\circ} \mathrm{C} \text {, Benzene }
$$

It was confirmed that p-MMA is little depolymerized by the above hydrolysis conditions.

The apparent number of grafted chains was calculated from the degree of grafting per $100 \mathrm{~g}$ of chitosan and the molecular weight of the graft ${ }^{8)}$.

\subsection{Analysis of Copolymer Composition}

The branched copolymer obtained using binary monomers was also isolated by the same method as described above and dissolved in acetone/DMF (6/4) solution and purified by reprecipitation.

Copolymer composition ratio was calculated by the following equation after measuring the nitrogen content by elementary analysis.

$$
\mathrm{N}(\%)=\left[14.01 / 53.06+\left(\mathrm{X} \times \mathrm{M}_{2}\right)\right] \times 100
$$

where $\mathrm{X}=$ mole number of $\mathrm{M}_{2}$ monomer per 1 mole of AN

$\mathrm{M}_{2}=$ molecular weight of $\mathrm{M}_{2}$ monomer.

\section{RESULTS AND DISCUSSION}

\subsection{Chitosan Sample}

\subsubsection{Amino group content}

The amino group content was determined from the results of the elementary analysis and the neutralization analysis.

The $\mathrm{N}$ content of the purified chitosan measured by the elementary analysis was $7.36 \%$. Then the degree of substitution of amino group, $X$, is estimated as 0.849 by the following equation.

$$
\mathrm{NX} / \mathrm{C}_{6} \mathrm{H}_{11} \mathrm{O}_{4} \mathrm{NX}+\mathrm{C}_{6} \mathrm{H}_{10} \mathrm{O}_{5}(1-\mathrm{X})=0.0736
$$

The purified chitosan (0.1g) was dissolved in $50 \mathrm{ml}$ of $0.03 \mathrm{~N} \mathrm{HCl}$, the solution was titrated with $0.5 \mathrm{~N} \mathrm{NaOH}^{9)}$. The amino group content was calculated from the volume of standard base consumed between inflection points at $\mathrm{pH} 4.4$ and 8.5. The amino group content was $554 \mathrm{mmol} / 100 \mathrm{~g}$ chitosan, equal to $89.2 \%$ of glucosamine molecular weight and almost coincided with the value estimated by the elementary analysis.

\subsubsection{Molecular weight}

The intrinsic viscosity of chitosan was measured in $0.2 \mathrm{M}$ acetic acid- $0.1 \mathrm{M}$ sodium chloride-4M urea aqueous solution. The molecular weight was then calculated ${ }^{10)}$. The viscosity average molecular weight and the degree of polymerization were $5.38 \times 10^{4}$ and 330 , respectively.

\subsection{Non-Catalytic Photo-Induced Graft \\ Copolymerization}

\subsubsection{Polymerization medium and wavelength}

In the presence of chitosan $(0.2 \mathrm{~g})$, the polymerization was carried out using $1.5 \mathrm{ml}$ of MMA and $\mathrm{H}_{2} \mathrm{O}$ or $20 \%$ DMF-aqueous solution (total volume, $12 \mathrm{ml}$ ) at $50^{\circ} \mathrm{C}$ for a fixed time.

As shown in Fig. 1, using a Q-tube, the total conversion and the degree of grafting increased with time, but the grafting efficiency decreased. These indicate that the graft polymerization proceeds mainly in the initial stage of the reaction.

DMF addition to the polymerization system increased the affinity of chitosan to monomer as compared with the aqueous system. Therefore, the induction period was shortened. On the other hand, the chain transfer to the solvent (DMF) also 


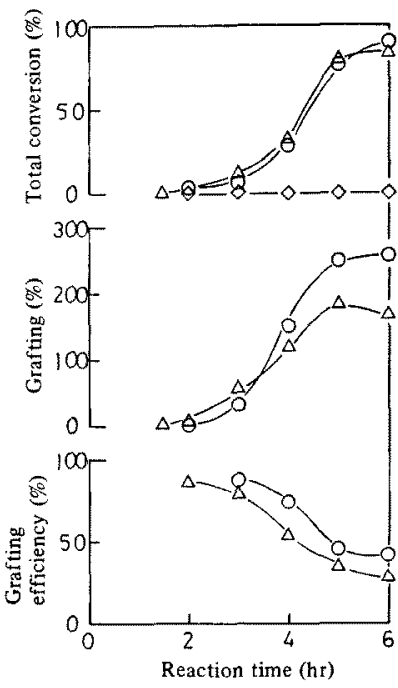

Fig. 1 Effect of reaction medium and wavelength on yield of polymer. Q-tube: (O), $\mathrm{H}_{2} \mathrm{O}$; $(\triangle), 20 \%$ DMF- $\mathrm{H}_{2} \mathrm{O}$; P-tube: $(\diamond), \mathrm{H}_{2} \mathrm{O}$; chitosan, 0.2g; MMA, $1.5 \mathrm{ml}$; total volume, $12 \mathrm{ml} ; 50^{\circ} \mathrm{C}$.

occurred, namely the branched chain length did not increase and thus the degree of grafting using 20\% DMF-aqueous solution became small when the conversion leveled off. In case of a P-tube, since the polymerization hardly occurred, it is clear that the light of $253 \mathrm{~nm}$ in wavelength participates in the polymerization.

\subsubsection{Monomer concentration}

In the presence of chitosan, the polymerization was carried out as a function of monomer concentration in an aqueous system at $50^{\circ} \mathrm{C}$ for $7 \mathrm{hr}$. The effect of the monomer concentration on the yield of polymerization, the branched chain length and the apparent number of grafted chains was investigated.

As shown in Fig. 2, the degree of grafting and the apparent number of grafted chains rapidly increased in the range of $1-1.5 \mathrm{ml}$ monomer concentration and became constant. Hence the grafting efficiency reached a maximum and then decreased. It was shown that the branched chain length increased from 1.3 to $1.8 \times 10^{6}$ with increasing monomer concentration.

\subsubsection{Chitosan concentration}

As described above, $1.5 \mathrm{ml}$ of MMA was polymerized changing the amount of chitosan at $50^{\circ} \mathrm{C}$

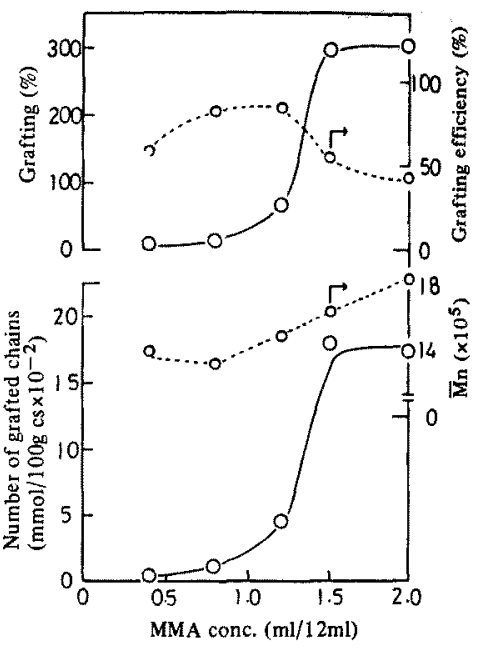

Fig. 2 Effect of monomer concentration on yield of polymer, $\bar{M} n$ and number of grafted chains. Chitosan, $0.2 \mathrm{~g} ; \mathrm{H}_{2} \mathrm{O},(12-\mathrm{MMA}) \mathrm{ml}$; Q-tube; $50^{\circ} \mathrm{C}, 7 \mathrm{hr}$.

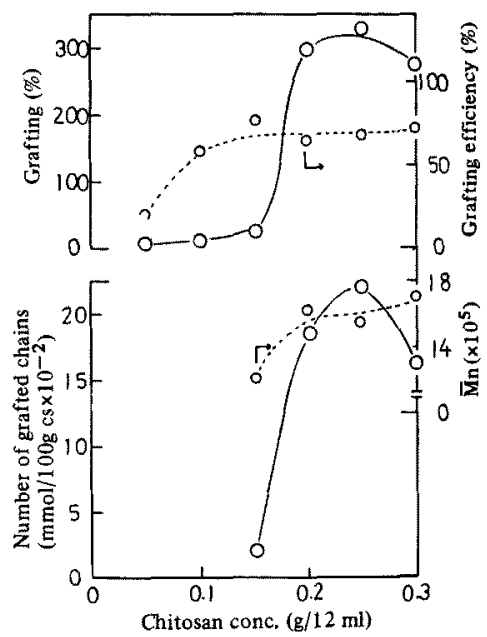

Fig. 3 Effect of chitosan concentration on yield of polymer, $\bar{M}_{n}$ and number of grafted chains. MMA, $1.5 \mathrm{ml} ; \mathrm{H}_{2} \mathrm{O}, 10.5 \mathrm{ml}$; Q-tube; $50^{\circ} \mathrm{C}, 7 \mathrm{hr}$.

for $7 \mathrm{hr}$ in a Q-tube.

Fig. 3 shows the effect of the chitosan concentration on the yield of polymerization, the branched chain length and the apparent number of grafted chains. The degree of grafting and the number of grafted chains increased in the range of $0.15-0.25 \mathrm{~g}$ chitosan concentration, and the grafting efficiency became 60-70\%. The chain length 
was $1.20-1.70 \times 10^{6}$. These values were somewhat lower than those obtained in the polymerization at various monomer concentrations. These suggest that the termination reaction takes place between the growing chain ends of the grafted polymers and the chitosan radicals. Namely, chitosan participates in not only initiation but also termination reaction. From these results, the photolysis of chitosan was examined.

\subsubsection{Photolysis of chitosan}

An infrared spectrum of a chitosan film prepared from the $1 \%$ acetic acid aqueous solution is shown in Fig. 4.

The $\mathrm{CH}$ stretching vibration attributed to pyranose ring appeared at $2950 \mathrm{~cm}^{-1}$ and the $\mathrm{NH}_{2}$ group deformation vibration at $1560 \mathrm{~cm}^{-1}$ The intensities of the transmitted radiation (I) and the incident radiation $\left(I_{0}\right)$ were measured by the method shown in the figure, and each absorbance (D) was calculated.

Fig. 5 shows a relationship between the absorbance ratio $\mathrm{D}_{\mathrm{NH}_{2}} / \mathrm{D}_{\mathrm{CH}}$ where $\mathrm{D}_{\mathrm{NH}_{2}}$ was divided by

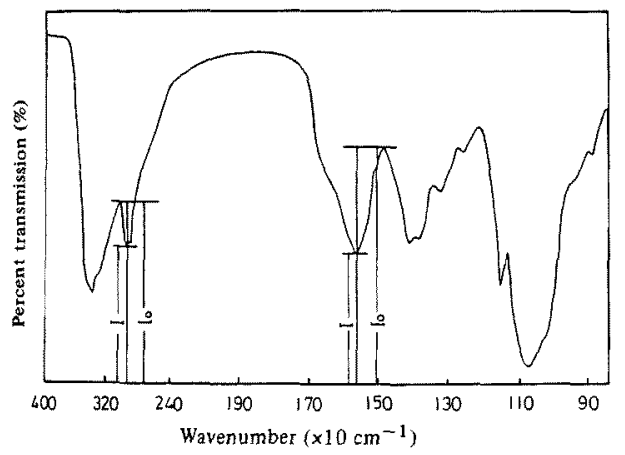

Fig. 4 Infrared spectrum of chitosan film.

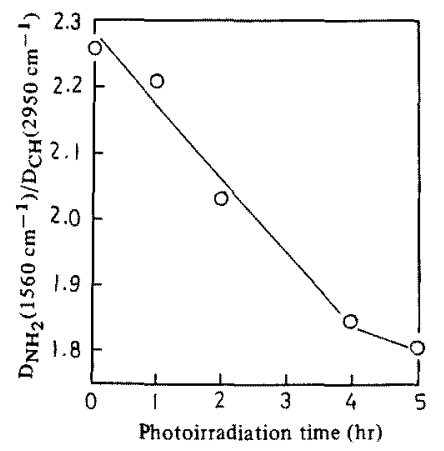

Fig. 5 Relation between $\mathrm{D}_{\mathrm{NH}_{2}} / \mathrm{D}_{\mathrm{CH}}$ and photoirradiation time. Q-tube; $50^{\circ} \mathrm{C}$.

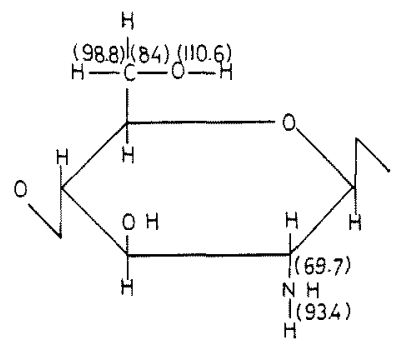

(kcal/mol)

Fig. 6 Dissociation energies of covalent bonds of chitosan.

$\mathrm{D}_{\mathrm{CH}}$ for correction of the chitosan film thickness and the irradiation time. It is apparent from the figure that the absorbance ratio decreased with an increase in irradiation time. Therefore, the elimination of the $\mathrm{NH}_{2}$ groups was considered.

Fig. 6 shows the dissociation energies of covalent bonds of glucosamine ${ }^{11)}$. Since $\mathrm{C}_{2}-\mathrm{N}$ bond dissociation energy, $69.7 \mathrm{kcal} / \mathrm{mol}$ is the lowest, the polymerization initiated by the elimination of $\mathrm{NH}_{2}$ groups by the photo irradiation is suggested. It is also considered that since the irradiation of $253 \mathrm{~nm}$ light can cause the scission of the glucosidic linkage of chitosan, the polymerization may start at the chain end ${ }^{8}$.

\subsection{Graft Copolymerization by Photosensitized Method}

In the presence of chitosan sample, the graft copolymerization was carried out as a function of initiator concentration in DMF- $\mathrm{H}_{2} \mathrm{O}$ system in a Q-tube at $50^{\circ} \mathrm{C}$ for a fixed time.

Fig. 7 shows the effect of the initiator concentration on the yield of polymerization. The total conversion and the degree of grafting increased as the initiator concentration increased. The value in the presence of azobisisobutylonitrile (AIBN), even a short reaction time, was higher than that for benzophenone $\left(\mathrm{Ph}_{2} \mathrm{CO}\right)$. Furthermore, the polymerization did not occur without the initiator under the same condition. The grafting efficiency decreased with increasing initiator concentration and was higher for $\mathrm{Ph}_{2} \mathrm{CO}$ than for AIBN.

The effect of initiator concentration on the branched chain length and the apparent number of grafted chains is shown in Fig. 8.

In each case of the initiators, the branched chain length was $1.20-1.30 \times 10^{6}$ These values were 


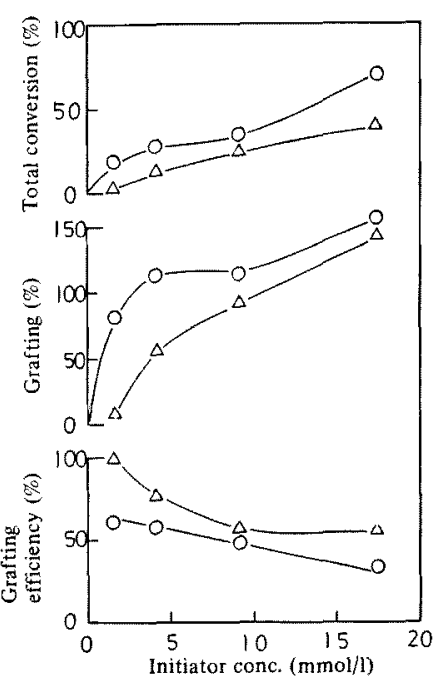

Fig. 7 Effect of initiator concentration on yield of polymer. (O), AIBN, $1.25 \mathrm{hr} ;(\triangle)$, $\mathrm{Ph}_{2} \mathrm{CO}, 4 \mathrm{hr}$; chitosan, $0.2 \mathrm{~g}$; MMA, $1.5 \mathrm{ml}$; $\mathrm{H}_{2} \mathrm{O}, 8.4 \mathrm{ml}$; DMF, $2.1 \mathrm{ml}$; Q-tube; $50^{\circ} \mathrm{C}$.

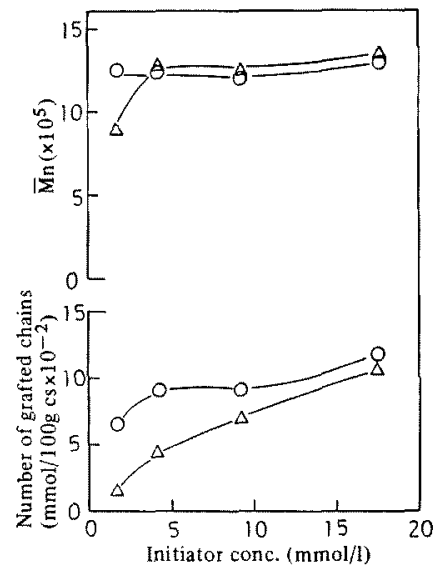

Fig. 8 Effect of initiator concentration on $\bar{M}$ and number of grafted chains. Polymerization conditions are the same as in Fig. 7.

small as compared with the non-catalytic photoirradiation method. On the other hand, the apparent number of grafted chains increased with an increase in initiator concentration, but small as compared with non-catalytic polymerization. Such a small number of the activation sites may be explained by the following reasons. By the photo irradiation, AIBN produces carbon radicals and carbonyl groups in $\mathrm{Ph}_{2} \mathrm{CO}$ are stimulated.
But in both cases, the abstruction of hydrogen from chitosan is weak. Namely, these are attributed to the different polymerization mechanisms from the non-catalytic method.

\subsection{Graft Copolymerization by Initiator Method}

In the presence of chitosan sample, the poly. merization was carried out as a function of initiator concentration in an aqueous system at $50^{\circ} \mathrm{C}$ for a fixed time. Then the effect of initiator concentration on the yield of polymerization was investigated.

As shown in Fig. 9, in the presence of ammonium persulfate (APS) and hydrogen peroxide (HPO), the total conversion and the degree of grafting, both increased with increasing initiator concentration, and became constant at 5 or 10 mmol. Polymerization activity of APS was higher than that of HPO and no polymerization occurred under the same conditions without the initiator. Hence, it is understood that the grafting efficiency decreased with an increase in initiator concentration and the value of HPO was higher than that of APS.

Fig. 10 shows the effect of the initiator concentration on the branched chain length and the apparent number of grafted chains.

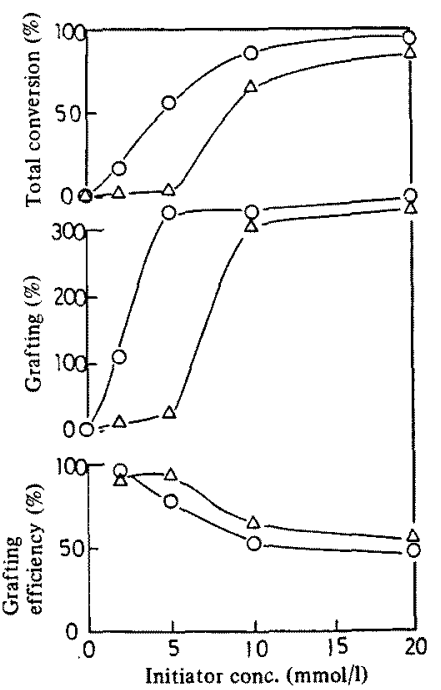

Fig. 9 Effect of initiator concentration on yield of polymer. (O), $\left(\mathrm{NH}_{4}\right)_{2} \mathrm{~S}_{2} \mathrm{O}_{8}, 1.5 \mathrm{hr} ;(\triangle)$, $\mathrm{H}_{2} \mathrm{O}_{2}, 6 \mathrm{hr}$; chitosan, $0.2 \mathrm{~g}$; MMA, $1.5 \mathrm{ml}$; $\mathrm{H}_{2} \mathrm{O}, 10.5 \mathrm{ml} ; 50^{\circ} \mathrm{C}$. 


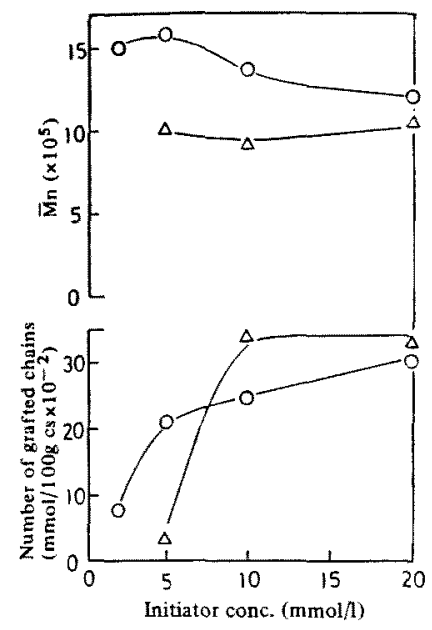

Fig. 10 Effect of initiator concentration on $\overline{\mathrm{M}} \mathrm{n}$ and number of grafted chains. Polymerization conditions are the same as in Fig. 9.

The branched chain length was $1.2-1.5 \times 10^{6}$ for APS and 0.9-1.0 $\times 10^{6}$ for HPO. On the other hand, the apparent number of grafted chains increased with increasing initiator concentration and these value was $2.5-3$ times that for the photo-sensitized method mentioned before. It is well known that APS ${ }^{12)}$ and $\mathrm{HPO}^{13)}$ produce sulfate ion radicals and hydroxy radicals, respectively and initiate polymerization.

From these results, the apparent number of grafted chains is the highest in the initiation method, intermediate in the non-catalytic photoinduced polymerization and the lowest in the photo-sensitized method (HPO $>$ APS $>$ AIBN $>$ $\mathrm{Ph}_{2} \mathrm{CO}$ ).

\subsection{Photo-Induced Graft Copolymerization using Binary Monomers}

\subsubsection{Yield of copolymer}

The polymerization was carried out in the presence of chitosan in a Q-tube as a function of the feed compositions of $\mathrm{AN}\left(\mathrm{M}_{1}\right.$ monomer) and St or MMA ( $\mathbf{M}_{2}$ monomer). Then the effect of AN mole fraction in the feed on the yield of copolymerization is discussed.

As shown in Fig. 11, in the copolymerization of AN-St, the total conversion and the degree of grafting were constant regardless of AN mole fraction in the feed. Whereas in the copolymerization of AN-MMA, these values decreased with

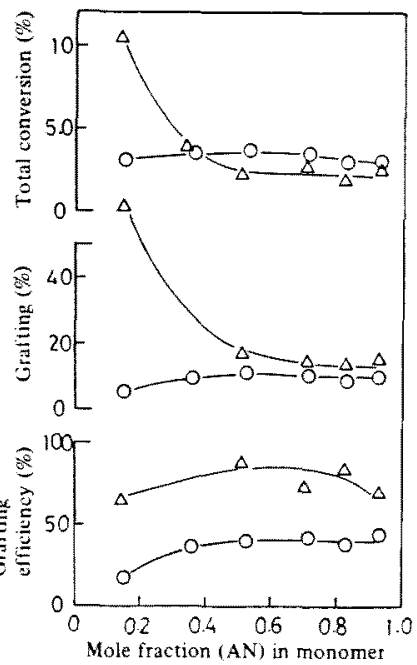

Fig. 11 Effect of mole fraction of $A N$ in the feed on yield of copolymer in copolymerization of $A N\left(M_{1}\right)-M_{2}$ monomer in the presence of chitosan. (O), AN.St, $2 \mathrm{hr}$;

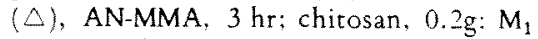
$+\mathrm{M}_{2}, 2 \mathrm{ml} ; \mathrm{H}_{2} \mathrm{O}, 10 \mathrm{ml}$; Q-tube; $50^{\circ} \mathrm{C}$.

increasing initial $A N$ mole fraction and the polymerizability of MMA was greater than that of AN. It was also found that the grafting efficiency of AN-MMA was considerably high as compared with AN-St.

\subsubsection{Alternating tendency of copolymer}

Composition curves for the grafted and ungrafted copolymers of AN-MMA and AN-St are shown in Fig. 12. Since infrared spectra of the grafted and ungrafted copolymers coincided with each other, it was confirmed that the hydrolysis of the copolymer did not occur when the branched polymer was isolated.

The composition curve for AN-MMA copolymer is below the azeotropic line and that for AN-St crosses this line, indicating that the copolymer composition is almost the same in the wide range of AN monomer in the feed.

The results of the monomer reactivity ratios calculated from Fineman-Ross method are shown in Table 1.

The products of monomer reactivity ratios $\left(r_{1} r_{2}\right)$ of the ordinary radical copolymerization are in the range of $0<r_{1} r_{2}<1$. The alternating tendency is detained for $r_{1} r_{2}$ near around zero. Consequenty, the alternating tendency is higher 


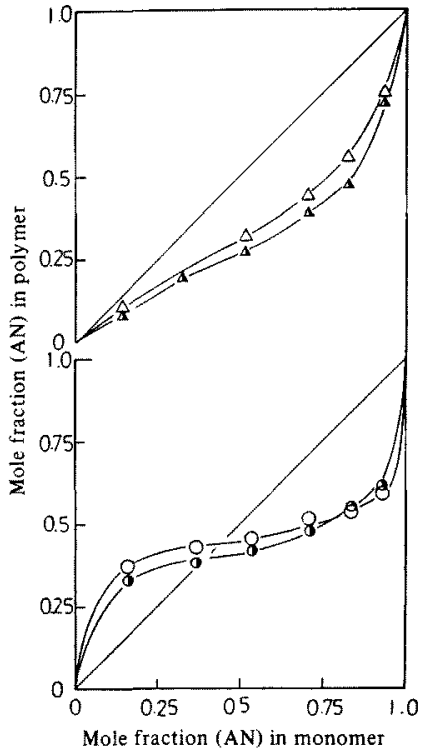

Fig. 12 Composition curves of graft (open mark) and homo (half solid mark) copolymer. Polymerization conditions are the same as in Fig. 11.

Table 1 Monomer reactivity ratio of graft and homo copolymer.

\begin{tabular}{ll|ccc}
\hline $\begin{array}{c}\text { Monomer } \\
\left(\mathrm{M}_{1}-\mathrm{M}_{2}\right)\end{array}$ & Copolymer & $\mathrm{r}_{1}$ & $\mathrm{r}_{2}$ & $\mathrm{r}_{1} \mathrm{r}_{2}$ \\
\hline \multirow{3}{*}{ AN - MMA } & Reference ${ }^{15)}$ & 0.15 & 1.2 & 0.18 \\
& Graft & 0.14 & 1.1 & 0.15 \\
& Homo & 0.11 & 1.3 & 0.14 \\
\hline \multirow{3}{*}{ AN - St } & Reference ${ }^{16)}$ & 0.04 & 0.41 & 0.02 \\
& Graft & 0.03 & 0.15 & 0.01 \\
& Homo & 0.05 & 0.54 & 0.03 \\
\hline
\end{tabular}

for AN-St than AN-MMA. It is considered that the former reaction is a combination of donor and acceptor type of monomer, thus the charge transfer complex was produced ${ }^{14)}$. The reference monomer reactivity ratios listed in Table 1 are those obtained by homogeneous copolymerization ${ }^{15,16)}$. It is interesting that the monomer reactivity ratios of the copolymer obtained in the heterogeneous system such as in our study are almost equal to these reference values. In case of
AN-St graft copolymerization, the alternating tendency of the resultant copolymer was somewhat different from that of the ungrafted copolymer. This suggests that some interactions exist between chitosan and monomer. Details of about this will be reported elsewhere. This paper was read at the Annual Meeting of the Society of Fiber Science and Technology, Japan, held in Tokyo, in May, 1986.

Acknowledgment: The authors deeply express their thanks to Kyowa-Yushi Co. Ltd. for providing us chitosan sample.

\section{REFERENCES}

1) K. Kojima, M. Yoshikuni and T. Suzuki; J. Appl. Polym. Sci., 24, 1587 (1979).

2) Y. Shigeno, K. Kondo and K. Takemoto; J. Macromol. Sci., Chem. A17, 571 (1983).

3) Y. Inaki, M. Otsuru and K. Takemoto; J. Macromol. Sci., Chem. A14, 823 (1980).

4) S. Kataoka and T. Ando; Kobunshi Ronbunshu; 37, 185 (1980).

5) S. Kataoka and T. Ando; Kobunshi Ronbunshu; 37, 375 (1980).

6) A. Takahashi and S. Takahashi; Kogyo Kagaku Zasshi, 74, 2541 (1971).

7) F. J. Welch; J. Polym. Sci, 61, 243 (1962).

8) A. Takahashi and S. Takahashi; Sen-i Gakkaishi, 33, T508 (1977).

9) L. J. Filar and M. G. Wirick; Proc. Int. Conf. Chitin/Chitosan, 1st, 1977, 169 (1978).

10) F. A. Rutherford; Proc. Int. Conf. Chitin/ Chitosan, 1st, 1977, 182 (1978).

11) T. Sasaki Ed. "Kagaku Binran Kisohen Il" Maruzene; Tokyo, 1966; P 1225.

12) S. M. Sankalla; Can. J. Chem., 40, 2249 (1962).

13) G. N. Richards; J. Appl. Polym. Sci., 5, 539 (1961).

14) A. Takahashi, S. Takahashi and E. Noguchi; Sen-i Gakkaishi, 32, T307 (1976).

N. G. Gaylord and L. C. Anand; Polymer Letters, 10, 285 (1972).

15) F. M. Lewis and C. Walling; J. Amer. Chem. Soc., 70, 1519 (1948).

16) F. M. Lewis, F. R. Mayo et al.; J. Amer. Chem. Soc., 67, 1701 (1945). 
光照射法および開始剤法によるキトサンへのグラフト共重合

工学院大学工業化学科高橋 璋, 菅原康里, 堀川義晃

キトサンへのMMAのグラフト重合において，

1）無触媒光照射法では誘導期が存在し，重合は主とし $\tau \mathrm{NH}_{2}$ 基の光分解により進行する。

2）光增感法ではAIBNのグラフト活性が $\mathrm{Ph}_{2} \mathrm{CO} の そ$ れに比ベて大きい。

3）開始剤法では過硫酸アンモニウムのグラフト活性が $\mathrm{H}_{2} \mathrm{O}_{2}$ K比へて大きいてとがわかった。
以上 3 㮔の重合法において，平衡特のグラフト率および 見加けの分畦数は，一般に

開始斉法>無触媒光热射法>光增感法の順になる。 $\mathrm{AN}-\mathrm{MMA}$ およびAN-Stの二成分の光グラフト重合 に粞いて，グラフトおよびホモポリマーのモノマー反応 性比は，均一系で得られた文献値しはば一致することが わかった。 